\title{
Synthesis of Oxytocin in Amnion, Chorion, and Decidua May Influence the Timing of Human Parturition
}

\author{
Rajni Chibbar, Freda D. Miller, and Bryan F. Mitchell \\ Departments of Obstetrics and Gynecology and of Anatomy and Cell Biology, The University of Alberta, Edmonton, AB, Canada T6G 2R7
}

\begin{abstract}
Despite the widespread clinical use of oxytocin (OT) as a potent and specific stimulant of labor, previous research data have not supported a role for OT in the physiology of normal human parturition. We have demonstrated synthesis of OT mRNA in amnion, chorion, and decidua using Northern blot analysis, ribonuclease protection assays, and in situ hybridization. Probes directed towards both the $3^{\prime}$ and $5^{\prime}$ ends of the gene have been used. Levels were highest in decidua with considerably less in chorion and amnion and very low levels in placenta. The transcript size in decidua appears to be 60-80 nucleotides smaller than the transcripts in amnion and chorion. OT gene expression in chorio-decidual tissues increased three- to fourfold around the time of labor onset. Estradiol stimulated synthesis of OT mRNA during in vitro incubation. These results support the hypothesis of a paracrine system involving OT and sex steroids within intrauterine tissues wherein significant changes could occur without being reflected in the maternal circulation. Such a paracrine system could rationalize a long-sought role for oxytocin in the physiology of human labor. These data may lead to novel approaches towards prevention or treatment of preterm labor. (J. Clin. Invest. 1993. 91:185-192.) Key words: fetal membranes $\bullet$ gene expression $\bullet$ paracrine $\bullet$ placenta $\bullet$ preterm labor
\end{abstract}

\section{Introduction}

Parturition in most mammalian species is preceded by a rise in estrogen and a decline in progesterone concentrations in maternal plasma (1). These events occur over several hours or days before parturition and lead to changes that increase myometrial contractility. These changes include an increase in myometrial oxytocin (OT) ${ }^{1}$ receptors and gap junction formation $(2,3)$. Immediately prior to labor onset, neurohypophyseal OT is released into the maternal circulation (4). This release is accompanied by increased production of prostaglandins from intrauterine tissues (5). The end result is coordinated uterine contractions resulting in delivery of the fetus.

Address reprint requests to Dr. Mitchell, Department of Obstetrics and Gynecology, The University of Alberta Hospitals, Edmonton, AB, Canada T6G 2 R7.

Received for publication 4 March 1992 and in revised form 24 June 1992.

1. Abbreviation used in this paper: OT, oxytocin.

\section{J. Clin. Invest.}

(C) The American Society for Clinical Investigation, Inc.

$0021-9738 / 93 / 01 / 0185 / 08 \$ 2.00$

Volume 91, January 1993, 185-192
In the human, the mechanisms regulating the timing of parturition are poorly understood. Most investigators have failed to show any significant changes in maternal plasma concentrations of estrogen, progesterone or OT preceding labor onset (6). We and others have hypothesized that the basic mechanisms underlying parturition may be similar in the human and other mammals but, in the human, events may occur in a paracrine fashion within intrauterine tissues, particularly within the amnionic and chorionic membranes and the maternal decidua. Thus, local alterations in the levels of paracrine regulatory factors could occur without being reflected in the maternal circulation. In this regard, we have demonstrated synthesis of estrogen and progesterone within intrauterine tissues and have shown a significant increase in the estrogen/progesterone ratio around the time of parturition (7-9). These tissues are also the sites of synthesis of prostaglandins that enhance myometrial contractions in labor $(10,11)$.

Despite the widespread use of OT to induce or augment human labor, there is considerable doubt about the physiologic role of OT in normal human parturition. This doubt is based on the following findings: $(a)$ most investigators have been unable to detect an increase in plasma OT before labor onset $(12,13) ;(b)$ there is no apparent correlation between plasma OT levels and myometrial activity (14); (c) plasma OT concentrations at labor onset are 10-1000-fold lower than the $K_{\mathrm{d}}$ of the myometrial OT receptors (15); and $(d)$ human labor occurs normally in cases of maternal posterior pituitary dysfunction and in the absence of OT from the fetal circulation (as in fetal anencephaly) (16). On the basis of this dichotomy, we hypothesized that, like the steroid hormones, local synthesis of OT within intrauterine tissues in late human gestation may play an important role in regulating parturition. This would rationalize the clinical observations regarding the physiologic nature of OT-stimulated labor with the evidence suggesting that OT does not regulate the timing of labor onset in an endocrine fashion.

In this article, we study OT gene expression in amnion, chorion laeve, and decidua around the time of parturition. The amnion and chorion are derived from fetal tissues. The amnion consists of a single layer of cuboidal epithelial cells on a loose connective tissue matrix. It is in immediate contact with the amniotic fluid on one surface and the underlying chorion on the other. The chorion laeve is an extension of trophoblast cells around the entire uterine cavity. Except at the placental site, it is intimately in contact with the maternal decidua which, in turn, is contiguous with the myometrium. Thus, this potential paracrine unit is ideally situated to mediate signals of fetal or maternal origin to the pregnant myometrium and hence to play an important role in the timing of parturition. Our experiments demonstrate by using Northern blot analysis, ribonuclease protection assays, and in situ hybridization that OT mRNA is synthesized within intrauterine tissues. Furthermore, OT gene expression is increased around the time of labor onset and 
a similar increase can be stimulated in vitro by estradiol. These findings support our hypothesis of a paracrine system involving OT and sex steroids that may stimulate myometrial contractions in the absence of changes in maternal plasma concentrations.

\section{Methods}

Tissue preparation. Upon approval from the Human Ethics Review Board, tissues were obtained from uncomplicated pregnancies at term immediately after spontaneous labor and delivery or at repeat cesarean section prior to labor. The amnion is easily separated from the choriodecidua and is essentially free of contamination with other cell types. The adherent decidua is carefully dissected from the chorion. On histologic examination, the decidua has very little contamination with chorion cells but the chorion may contain up to $20 \%$ decidual cells (17). After separation, the tissues, along with a sample of placental tissue, were immediately frozen in liquid nitrogen or processed for in situ hybridization. Corpora lutea were obtained from two patients who underwent ovariectomy. Human pituitaries (females of reproductive age) were removed and frozen in liquid nitrogen at the time of postmortem examination. Care was taken not to include any hypothalamic tissue in the sample.

Tissue explant cultures. By using a sterile cork borer, $2.5-\mathrm{cm}$ disks of unseparated amnion and chorio-decidual tissue were excised and incubated in "pseudo-amniotic fluid" $(18)$ at $37^{\circ} \mathrm{C}$ in $95: 5$ air $/ \mathrm{CO}_{2}$ for $12 \mathrm{~h}$. This medium consists of electrolytes, glucose, urea, and albumin in concentrations similar to human amniotic fluid. Estradiol was added to the medium in concentrations of $0,0.1$ and $1.0 \mathrm{nM}$. We have chosen this culture system because it allows study of the intact tissues in their own matrix and avoids the potentially artifact-producing procedures of cell dispersion and culture. In this system, the cells remain metabolically, endocrinologically, and histologically intact for at least 5 d (17).

Northern blot analysis. Total RNA was isolated from the human tissues by the guanidine isothiocyanate/cesium chloride gradient technique and poly $\mathrm{A}^{+}$RNA was obtained using oligo $\mathrm{dT}$ cellulose columns (19). $5 \mu \mathrm{g}$ of poly $\mathrm{A}^{+}$RNA was fractionated on $1.5 \%$ agarose gel in the presence of $1.0 \mathrm{M}$ formaldehyde and transferred to nitrocellulose filters (20). The 3 '-specific human OT cDNA probe $(21)$ used in this study is $187 \mathrm{bp}$ in length, including a 30-bp linker. It corresponds to the final 60 nucleotides of exon 3 coding for the carboxy terminal end of the neurophysin-I molecule and the adjacent sequences of the $3^{\prime}$ untranslated region. This is the area with least homology with the vasopressin gene and renders the probe specific for the oxytocin gene. The rat hypothalamic RNA was obtained and the antisense OT RNA probes were prepared as previously described (22) with SP6 RNA polymerase (Promega Corp., Madison, WI) and [ $\left.{ }^{32} \mathrm{P}\right] \mathrm{CTP}$ (New England Nuclear, Boston, MA, $800 \mathrm{Ci} / \mathrm{mmol}$ ) under conditions described by Melton et al. (23). The antisense RNA probes were hybridized to the immobilized RNA in the presence of $50 \%$ formamide, $50 \mathrm{mM}$ PIPES ( $\mathrm{pH} 6.8$ ), $5 \times$ Denhardt's, $0.1 \%$ SDS, $100 \mathrm{mg}$ of salmon sperm and herring sperm DNA and yeast tRNA at $65^{\circ} \mathrm{C}$ for $12-16 \mathrm{~h}(22)$. Filters were subsequently washed to a stringency of $0.05 \times \mathrm{SSC}$ at $65^{\circ} \mathrm{C}$. Nitrocellulose filters were exposed to XAR or XRP X-ray films (Eastman Kodak Co, Rochester, NY) for 1-7 d. To confirm that equivalent amounts of RNA were loaded on each lane, blots were reprobed with ${ }^{32} \mathrm{P}$-labeled $\gamma$-actin cRNA probes. The $\gamma$-actin probe consists of 300 nucleotides of distal 3'-untranslated region of the cDNA clone pHF $\gamma \mathrm{A}$ (24).

In situ hybridization. Tissues were immersion fixed, cryoprotected, and sectioned onto chromalum-subbed slides. After fixation in phosphate buffer containing $4 \%$ paraformaldehyde for $20 \mathrm{~min}$ and treatment with proteinase $\mathrm{K}$, sections were prehybridized and hybridized with the ${ }^{35} \mathrm{~S}$-labeled 3 '-specific OT antisense cRNA probe at $42^{\circ} \mathrm{C}(22)$. The hybridization solution was similar to that used for Northern blot analysis except for the presence of $20 \mathrm{mM}$ DTT. After RNase treatment $(200 \mu \mathrm{g} / \mathrm{ml})$ and washings up to $0.1 \% \mathrm{SSC}$ at $42^{\circ} \mathrm{C}$, slides were exposed to XAR X-ray film for 1-2 $d$ to determine the optimum time of exposure with NTB-2 (Eastman Kodak Co., Rochester, NY). Slides were dipped in NTB-2 emulsion and exposed for $2-5 \mathrm{~d}$ at $4^{\circ} \mathrm{C}$. Sections were developed, counterstained with hematoxylin and eosin, and analyzed by darkfield and brightfield microscopy. Control slides were incubated with sense cRNA probe of similar specific activity.

Ribonuclease protection assays. Total RNA from various tissues was isolated as described (19). The ribonuclease protection assays were performed using a modification of a previously published technique (19). Total RNA (70-100 $\mu \mathrm{g}$ ) was hybridized to gel-purified human OT antisense ${ }^{32} \mathrm{P}$-labeled cRNA probe in $80 \%$ formamide and $20 \%$ PIPES for $16 \mathrm{~h}$ at $55^{\circ} \mathrm{C}$. Template DNA was removed from the probe by treatment with ribonuclease-free $D N a s e$. After incubation with ribonucleases $\mathrm{A}(2.5 \mu \mathrm{g} / \mathrm{ml})$ and $\mathrm{T}_{1}(330 \mathrm{U} / \mathrm{ml})$ (Boehringer-Mannheim, Montreal, $\mathrm{PQ}$ ), protected fragments were analyzed on $6 \%$ denaturing polyacylamide gels. The gel was exposed to XAR X-ray film with an intensifying screen for 1-7 d.

After extraction of RNA from the tissues, stock solutions were made for each sample and the concentration of RNA measured by spectrophotometry. For each gel, equal amounts of total RNA were used for each sample. To confirm that equal amounts of RNA were applied, in some experiments, the protection assays were performed using a probe to $\gamma$-actin, a constitutive component of these tissues which we assume to be similarly abundant in the fetal membrane tissues and not to change with parturition. In that this mRNA is more abundant than the OT mRNA, smaller aliquots of RNA were necessary. $10 \mu \mathrm{g}$ of total RNA was used with the $\gamma$-actin probe. In these experiments the $\gamma$-actin probe corresponds to 270 nucleotides of the carboxyl-terminal coding region, 130 nucleotides of the 3 ' untranslated region, and 130 nucleotides of vector sequences.

The $5^{\prime}$ human OT probe used in these studies consists of $\sim 360$ nucleotides corresponding to the OT peptide coding region of exon 1 and all of exon 2 .

For comparing amounts of OT mRNA between the cesarean section and spontaneous labor groups and for assessing the response to estrogen, laser densitometry was used to give quantitative data. Because of the heterogeneous variance in the small number of samples, statistical comparisons were performed using the Mann-Whitney $U$ test with statistical significance being defined as a $P$ value $<0.05$.

\section{Results}

To determine whether OT mRNA is synthesized in intrauterine tissues, amnion, chorion, and decidua were dissected and RNA was isolated. OT mRNA was present in all three of these tissues (Fig. $1 a$ ). Levels were highest in maternal decidua and were approximately equal in chorion and amnion. We also examined a number of other human tissues and cell lines. OT mRNA was also expressed in human ovary, as previously described (25), as well as in the pituitary and placenta, although levels were much lower than in the intrauterine tissues (Fig. 1 a). No OT mRNA was detected in the human 4A neuroblastoma cell line or in rat cerebral cortex, even upon prolonged exposures. Hybridization of the same Northern blot to a probe specific for $\gamma$-actin mRNA indicated that approximately equal amounts of poly $\mathrm{A}^{+}$RNA were present in each lane (Fig. $1 b$ ). Using the 3 '-specific probe for human $\gamma$-actin, no hybridization was detected in either the rat or human neural tissues.

The cellular localization of OT mRNA was performed by in situ hybridization (Fig. 2). Amnion, chorion, and decidua all demonstrated hybridization to the antisense cRNA probe (Fig. $2 b$; for histology, see Fig. $2 a$ ). The epithelial layer of amnion demonstrated a small amount of specific hybridization. The chorionic membrane, originating from the outer cell mass of the blastocyst, consists of connective tissue and a layer of trophoblast 4-10 cells thick. In contrast to the very low levels of 


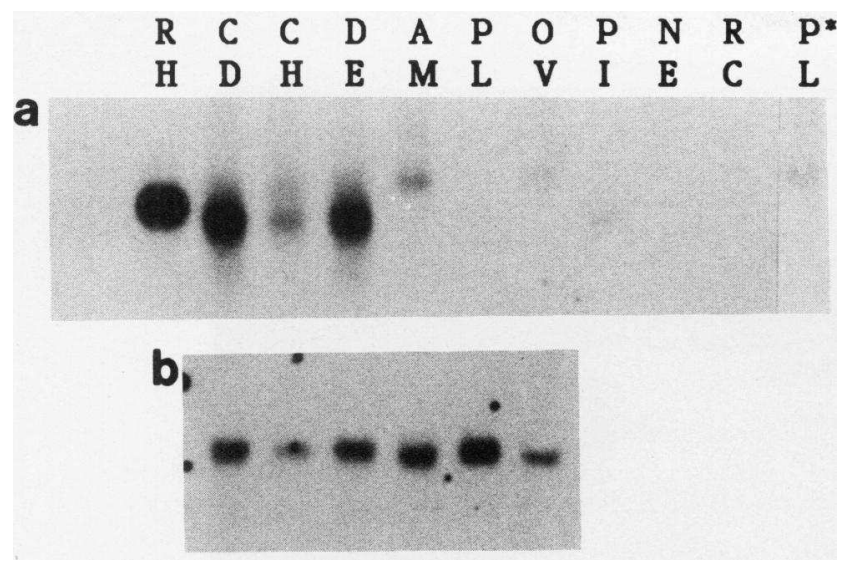

Figure 1. (a) Northern blot analysis of OT mRNA in human tissues: $R H$, rat hypothalamus (positive control); $C D$, chorio-decidua; $C H$, chorion; $D E$, decidua; $A M$, amnion; $P L$, placenta; $O V$, ovary; $P I$, pituitary; $N E$, human neuroblastoma $4 \mathrm{~A}$ cell line (negative control) and $R C$, rat cortex. $(b)$ Hybridization of the same blot with human $\gamma$-actin probe to demonstrate the relative amounts of RNA in each lane from the $C D$ to $O V$ lanes. $P L^{*}$ is a $7-d$ exposure of the placental lane compared to a 36-h exposure for the other lanes. The predominant transcript in decidua is $60-80$ nucleotides smaller than the transcript seen in amnion, ovary, and placenta.

hybridization in the placental trophoblast (data not shown), the chorionic trophoblast shows abundant silver grains denoting presence of OT mRNA. The maternally derived decidua demonstrated the highest levels of hybridization which appeared to be concentrated in the deeper layers lying nearest the myometrium. It is not possible with our current histology to identify with certainty the specific cell types synthesizing OT mRNA. Control incubations using the sense probe demonstrated only minimal background (Fig. $2 c$ ).

To confirm these findings and to quantitate the relative levels of OT mRNA in different tissues, ribonuclease protection assays were performed (Fig. 3). Hybridization of $100 \mu \mathrm{g}$ of total RNA to a ${ }^{32} \mathrm{P}$-labeled OT cRNA probe produced a protected band of $\sim 160$ nucleotides, the expected size, in amnion, chorion, decidua, and placenta (Fig. $3 a$ ). As with Northern blot analysis, the decidua expressed greater levels of OT mRNA than either amnion or chorion. Specific hybridization to placental and ovarian mRNA (Fig. $3 a$ ) was detected only after prolonged exposures. No protected band was detected following hybridization of the OT cRNA probe to tRNA or to total RNA isolated from rat hypothalamus, indicating that even the $85 \%$ homology between the human and rat mRNAs was not sufficient to protect the human probe in this assay. To ensure the validity of these quantitative comparisons, ribonuclease protection assays were performed with a probe specific for $\gamma$-actin mRNA. Approximately equal amounts of $\gamma$-actin mRNA were present in the amnion, chorion, decidua and placenta whereas there was somewhat less RNA in the ovary lane (Fig. $3 c$ ).

Ribonuclease protection assays also were performed with a 5 ' probe that included the coding region for the OT peptide. A protected fragment was detected in total RNA from the choriodecidua (Fig. $3 b$ ), indicating that the OT mRNA detected in this tissue could produce the biologically active peptide.

These data suggest that locally synthesized OT may participate in a paracrine mechanism regulating the timing of labor onset. To test this hypothesis, we isolated total RNA from chorio-decidua obtained at elective repeat cesarean section $(C S)$ before labor ( $38.4 \pm 0.9$ wk of gestation, SEM) or after spontaneous onset of labor $(S L)$ and vaginal delivery $(40.3 \pm 0.6)$ and determined levels of OT mRNA. Ribonuclease protection assays of equal amounts of total RNA from seven prelabor and six postlabor samples revealed that OT mRNA levels were consistently higher in the chorio-decidua after parturition (Fig. 4, $a$ and $b$ ). Scanning laser densitometry revealed that SL tissues contained three- to fourfold higher levels of OT mRNA than did CS tissues (Fig. $4 a ; 1.8 \pm 0.2$ vs. $0.6 \pm 0.1 \mathrm{U}, P$ $<0.008$ and Fig. $4 b ; 3.0 \pm 0.5$ vs. $0.8 \pm 0.7 \mathrm{U}, P<0.04)$. Similarly, when levels of OT mRNA were normalized by comparison with levels of $\gamma$-actin mRNA in the same samples (Fig. 4 $c$ ), as determined by ribonuclease protection assays, the ratios of OT to $\gamma$-actin were significantly higher in SL compared to CS tissues $(P<0.03)$. OT mRNA levels were similar in all of the different postlabor chorio-decidua samples, but were somewhat variable in prelabor samples, possibly owing to differences in the proximity to the time when spontaneous labor would have occurred in the elective cesarean section patient population.

One potential mediator of this increase in OT mRNA observed in the postlabor samples is estradiol. We have previously demonstrated that estradiol biosynthesis increases in human fetal membranes around the time of parturition (7). Estradiol increases synthesis and release of OT from the neurohypophyseal system $(20,26,27)$. To determine whether estradiol can increase OT mRNA levels in chorio-decidua, we incubated full-thickness membrane explants (amnion, chorion, and decidua) in the presence of various concentrations of estradiol for $12 \mathrm{~h}$. Ribonuclease protection assays of equal amounts of total RNA isolated from these explants indicated that estradiol $(0.1$ and $1.0 \mathrm{nM}$ ) increased OT mRNA content relative to controls incubated for the same period of time with no estradiol (Fig. 5).

\section{Discussion}

The results of this study demonstrate a new peripheral site of OT synthesis, the human intrauterine tissues of both fetal and maternal origin. The fetal membranes and maternal decidua are believed to play an important role in the metabolic events leading to the initiation of parturition (28). The juxtaposition of these tissues next to the myometrium situates them ideally to influence myometrial contractility. The demonstration of a three- to fourfold increase in OT gene expression following labor and delivery and its regulation in vitro by estradiol strengthens our hypothesis that local synthesis of OT could stimulate uterine contractions in a paracrine fashion without increasing circulating maternal OT concentrations.

The Northern blot and ribonuclease protection analyses using the 3 '-directed probe indicate that OT mRNA is synthesized predominantly in decidua, with much lower levels in chorion and amnion. We cannot determine what proportion of the chorion OT mRNA may be due to contamination with decidual cells, but in situ hybridization demonstrated some OT mRNA in the trophoblast layers of the chorion. The in situ hybridization experiments also suggested that decidual cells lying next to the underlying myometrium expressed higher OT mRNA levels than did cells lying closer to the chorion. Thus, 

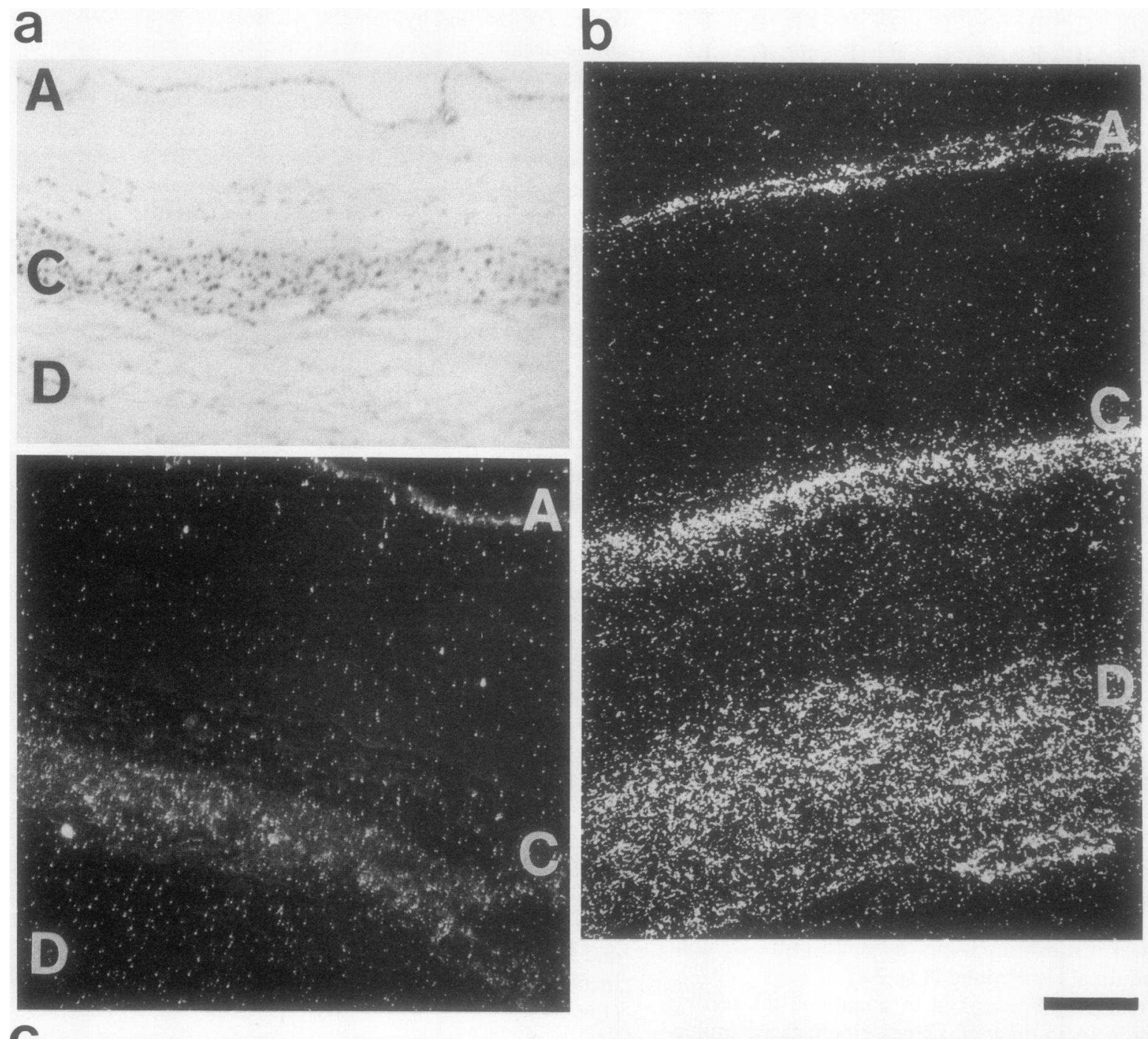

Figure 2. In situ hybridization for OT mRNA in human intrauterine tissues. ( $a$ ) Brightfield photomicrographs of human amnion $(A)$, chorion $(C)$, and decidua $(D)$ to demonstrate the histology of the tissues. $(b)$ Darkfield photomicrograph using an antisense cRNA probe demonstrating the specific hybridization to OT mRNA in amnion, chorion, and decidua. $(c)$ Darkfield photomicrograph of human amnion, chorion, and decidua hybridized with a labeled sense cRNA probe to act as a control for $b$. Specific activity of the probe and photographic conditions are similar to that for $b$. All photomicrographs are at the same magnification. Bar, $20 \mu \mathrm{m}$.

the highest local levels of OT synthesis may occur in the region immediately adjacent to the putative target organ, the myometrium.

Recently, it has been demonstrated that mRNA derived from the rat testis vasopressin gene is nontranslatable and corresponds to exons 2 and 3 without exon 1, the exon coding for the vasopressin peptide (29). To ensure that exon 1 of the OT gene was transcribed in fetal membrane tissues, we performed ribonuclease protection assays to demonstrate hybridization to the $5^{\prime}$ OT probe. The results (Fig. $3 b$ ) prove that these tissues transcribe the regions of the OT gene that codes for the OT peptide and rule out the possibility of splice variation of OT mRNA.

An interesting observation in our study was the difference in size of OT transcripts from different intrauterine tissues. Chorion appeared to produce both of the transcripts although we cannot exclude the possibility that the smaller of the two is due to contamination of the chorion tissue with adherent decidua. Decidual OT mRNA is $60-80$ nucleotides smaller than that synthesized by chorion, amnion, ovary, and placenta. In the chorio-decidua, this difference is not likely due to differences in the coding region of the mRNA since both the 5'- and 3'-specific probes were completely protected by RNA from these tissues. The difference in size may be due to a variation in the poly (A) tail length, as has previously been noted in bovine hypothalamic and ovarian OT mRNA (30). Differences in poly(A) tail length may provide a mechanism for increasing OT mRNA stability $(31,32)$ and hence, synthesis during times of increasing physiological requirement for this hormone. Support for this hypothesis derives from studies demonstrating that OT mRNA poly(A) tail length increased during pregnancy and lactation (33) and in response to osmotic stimuli 

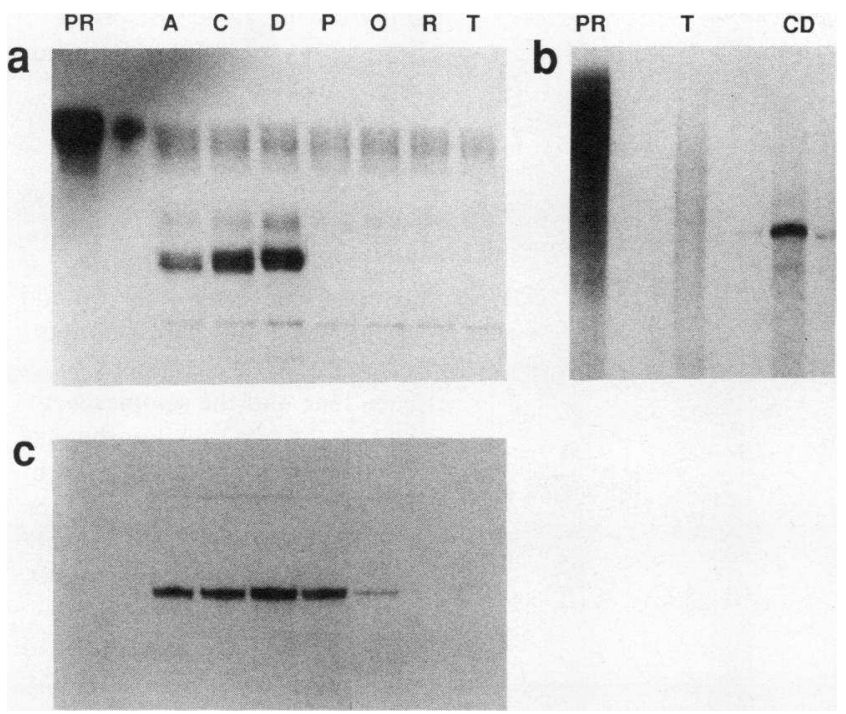

Figure 3. Ribonuclease protection assay for OT mRNA in human tissues using a probe specific for the OT gene. (a) samples hybridized with a 3 '-specific probe. Lanes correspond to the probe $(P R)$, amnion $(A)$, chorion $(C)$, decidua $(D)$, placenta $(P)$, and ovary $(O)$. Negative controls are rat hypothalamus $(R)$ and tRNA $(T)$. Protected bands were not observed in the placental and ovarian samples at this exposure time: prolonged exposure times were required to detect positive signals in these tissues. $(b)$ Ribonuclease protection assay using a 5'-specific probe corresponding to parts of exons 1 and 2 coding for the OT peptide and the amino-terminal end of neurophysin I. The lanes contain the probe $(P R), \operatorname{tRNA}(T)$ used as a negative control and a sample of chorio-decidua $(C D)$ obtained after the spontaneous onset of labor. The lanes adjacent to $C D$ contain a small amount of RNA that has spilled from lane $C D$. $(c)$ Ribonuclease protection assay performed with a $\gamma$-actin probe to demonstrate the amounts of RNA in each of the sample lanes in $a$. Relatively equal amounts of RNA are present in the lanes containing samples $A, C$, $D$, and $P$, whereas the lane containing the sample from human ovary has somewhat less RNA. The human probe was not protected by rat hypothalamic RNA or tRNA.

(34). The two sizes of transcripts noted in our studies may thus indicate tissue-specific differences in posttranscriptional regulation of OT synthesis.

Our results also demonstrate that OT mRNA is present in the human pituitary and corpus luteum thus supporting previous studies in mammals (35-38). The human pituitary transcript was smaller in size than the amnion and ovarian transcript. In this regard, Mohr et al. (38) demonstrated that OT transcripts found in rat posterior pituitary were smaller than those found in the hypothalamus. It is not known whether OT is synthesized in the human pituitary or transported axonally from the hypothalamus as in the rat (39).

Comparison of prelabor and postlabor tissues revealed that OT mRNA levels were higher after the spontaneous onset of labor. We have used ribonuclease protection assays to make these comparisons not only because of the specificity of these assays but also because we feel that the solution hybridization step provides a better basis for quantification than Northern blot analysis. Quantification by laser densitometry revealed that the three- to fourfold increase in OT mRNA seen in the tissues after the spontaneous onset of labor was statistically significant. The OT mRNA levels tended to be similar in all postlabor chorio-decidua samples, suggesting that a maximal level of gene expression had occurred. However, there was considerable variability in the prelabor samples which may be because these samples were obtained at varying intervals before spontaneous labor would have occurred. Although we cannot determine if the increase in OT gene transcription was a cause or result of labor, this finding is consistent with the hypothesis that increased local synthesis of OT may play a role in the physiology of human parturition. A recent study (40) has demonstrated an increase in pulsatile bursts of OT in the maternal circulation prior to spontaneous labor. However, the origin of maternal circulatory OT is not known nor is its role in the initiation of labor.

The data of Fig. 5 suggest that estradiol may regulate OT gene expression in fetal membranes. Previous studies have demonstrated that an increase in plasma estradiol at the time of parturition (1) and sexual maturation stimulates hypothalamic OT synthesis and release in the rat (19). Furthermore, the human OT promoter contains a functional estradiol-responsive element (41). Human amnion, chorion, and decidua are all steroidogenic tissues that produce estrogen and progesterone primarily from sulfurylated precursors (7). We have demonstrated that the rate of estrogen production and the local estrogen/progesterone ratio increases in fetal membranes around the time of parturition (9). In addition, estradiol receptors are present in decidua and increase in response to treatment with the progesterone receptor antagonist RU486 (42). Thus, our results demonstrating that estradiol increased OT gene expression in amnion-chorion-decidua explant cultures may have physiologic relevance.

Estradiol is not the only factor that is likely to regulate intrauterine OT biosynthesis. Several studies suggest an interrelationship between OT and prostaglandins. Stimulatory prostaglandins are synthesized within decidua and amnion, and their production increases around the time of labor onset $(43,44)$. OT stimulates prostaglandin synthesis from decidua and amnion, and this stimulatory activity is greater in tissues collected after labor than before labor onset (45-47). Decidual and myometrial cells also contain OT receptors that increase greatly around the time of parturition (48-50). The resultant increased sensitivity of the uterus to OT may be an important step not only in the second stage of labor, when circulating serum concentrations of OT are increased, but also in the initiation of labor. A close temporal relationship between increased OT responsiveness and uterine prostaglandin synthesis has been demonstrated in the rat (46). Induction of labor with OT in women is successful only when OT infusion is associated with an increase in production of $\operatorname{PGF}_{2 \alpha}(51,52)$. Suppression of prostaglandin synthesis decreases myometrial OT responsiveness as well as OT binding sites (43). These findings support the hypothesis that OT synthesized in decidua may act in an autocrine or paracrine fashion to stimulate intrauterine prostaglandin biosynthesis. In turn, prostaglandins stimulate synthesis of OT receptors and gap junction formation in myometrial cells $(53,54)$.

Inappropriate induction of OT synthesis in fetal membranes may also play an important role in the onset of premature labor. It is possible that locally synthesized OT may be a mediator of the pathophysiologic process causing premature 

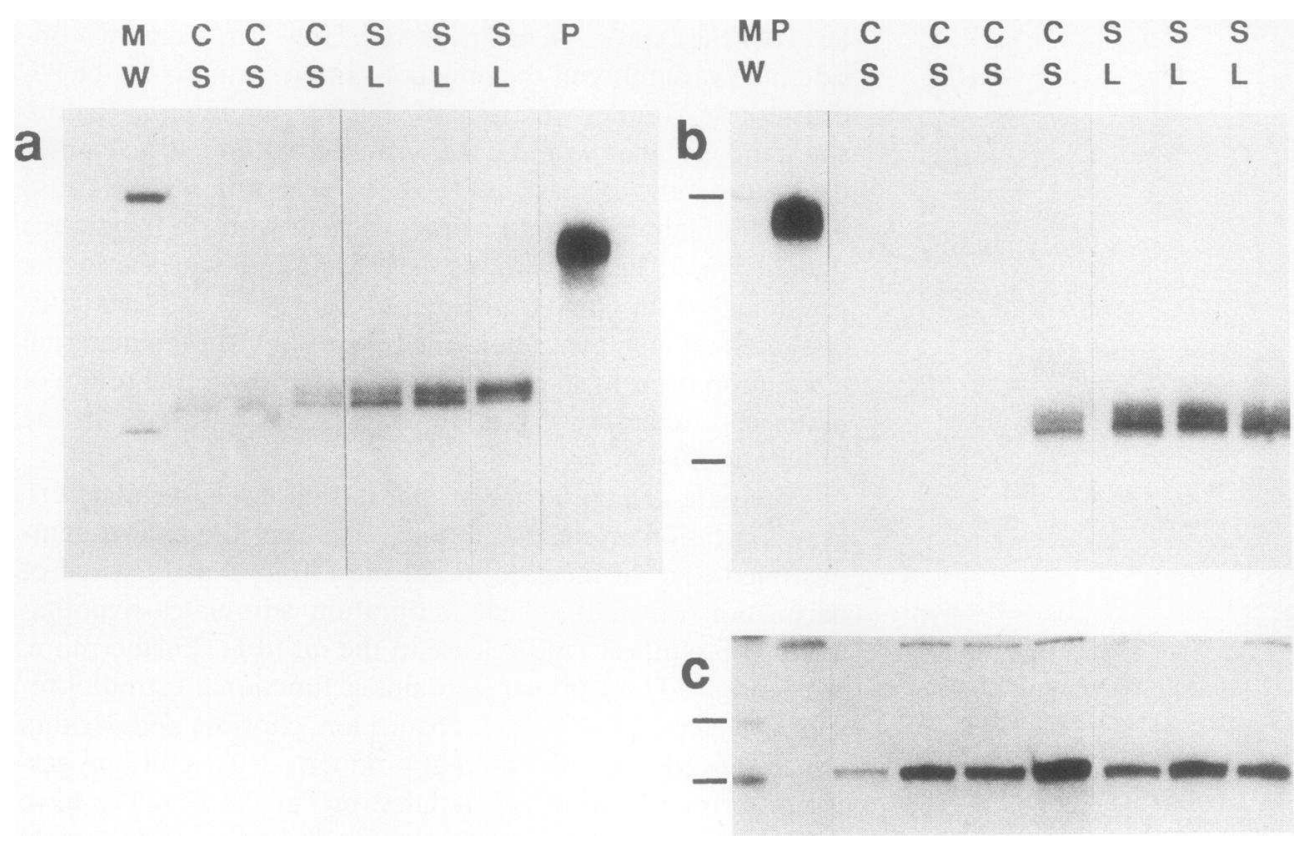

Figure 4. Ribonuclease protection assays using RNA from human chorio-decidua collected at elective cesarean section ( $C S$ ) at term but before labor onset or at term after the spontaneous onset of labor $(S L)$ and vaginal delivery. (a) Three separate samples from each of the $C S$ and $S L$ groups. Equivalent amounts of total RNA were applied to each lane and the samples were run on the same gel. For the sake of clarity, the pictures have been spliced to eliminate empty lanes. (b) Similar to $a$ showing several additional and different samples. (c) The same samples as $b$ but hybridized to a $\gamma$-actin probe to show relative amounts of RNA in each lane. In all panels, $P$ identifies the undigested probe and $M W$ indicates the DNA molecular weight standards ( 220 and 152 nucleotides for $a$ and $b ; 396$ and 344 nucleotides for $c$ ). labor after infection of the fetal membranes $(55,56)$. Mediators of the immune system stimulate synthesis and release of OT from the neurohypophysis. Christensen et al. (57) demonstrated a dose-dependent effect of interleukin- $1 \beta$ on the in vitro release of OT from the rat neurohypophysis. An increase in plasma levels of OT occurs after intravenous injection of lipopolysaccharides (58). Of interest in this regard, the promoter region of the rat $\mathrm{OT}$ gene contains an interferon response element (59), suggesting the possibility of direct regulation of the OT gene by the products of the immune system. In addition, cytokines (interleukins, tumor necrosis factor) and lipopolysaccharides stimulate prostaglandin biosynthesis from intrauterine tissues (60-63). Early induction of local OT synthesis in fetal membranes by any of these factors may have important consequences for the timing of parturition.

In conclusion, our findings suggest a potentially important role for OT in the physiology of human parturition. They also rationalize how this hormone, with such specific and potent

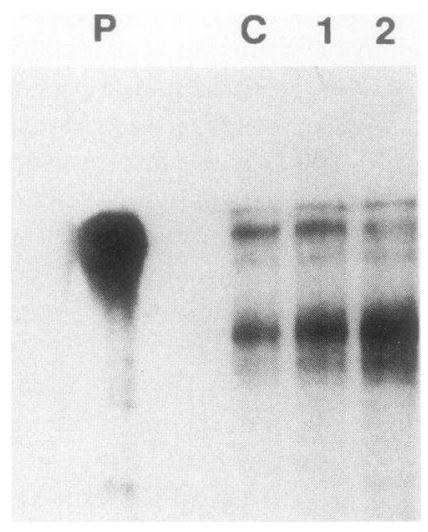

Figure 5. Ribonuclease protection assay for OT mRNA from explant cultures of full thickness human amnion and chorio-decidua incubated in the presence or absence of estradiol. The tissues were obtained at elective cesarean section and incubated for $12 \mathrm{~h}$ in pseudo-amniotic fluid. The lanes represent the probe $(P)$ or RNA extracted from the tissues incubated in the absence $(C)$ or presence of 0.1 and 1.0 nM estradiol (lanes $l$ and 2 , respectively). ability to stimulate human myometrial contractions, may play a pivotal role in labor onset in the absence of significant changes in maternal plasma concentrations. The results are compatible with the hypothesis of an intrauterine paracrine system with positive interactions among OT, estradiol, and prostaglandins. The local increase in the estrogen/progesterone ratio in late pregnancy may activate OT gene transcription and increase the number of OT receptors in myometrium and decidua. The latter may sensitize both the myometrium and the decidua to any local OT, thereby leading to increasing contractile activity and increasing production of stimulatory prostaglandins, respectively. The increased prostaglandins would directly stimulate the myometrium and potentially lead to further increases in production of OT and its receptor. This coordinated interaction involving estradiol, OT, and prostaglandins in human fetal membranes could ultimately result in the onset of parturition. Given that premature labor remains the major contributing factor to perinatal mortality and morbidity, and that potent OT antagonists recently have been developed ( 64 , 65 ), this information may be important both in understanding the regulation of human parturition and in preventing preterm delivery. Further studies elucidating regulatory mechanisms controlling OT gene expression in intrauterine tissues may lead to new strategies to prevent or treat premature labor.

\section{Acknowledgments}

These studies were supported by grants from the Medical Research Council of Canada and the Alberta Heritage Foundation for Medical Research (AHFMR) to Drs. Mitchell and Miller. Dr. Miller is an AHFMR scholar.

\section{References}

1. Thorburn, G. D., and J. R. G. Challis. 1979. Endocrine control of parturition. Physiol. Rev. 59:863-917. 
2. Fuchs, A. R., S. Periyasamy, M. Alexandrova, and M. S. Soloff. 1983. Correlation between oxytocin receptor concentration and responsiveness of oxytocin in pregnant rat myometrium: effects of ovarian steroid. Endocrinology. 113:742-749.

3. Garfield, R. E., S. Rabideau, J. R. G. Challis, and E. E. Daniel. 1979. Hormonal control of gap junctions in sheep myometrium. Biol. Reprod. 21:9991007.

4. Fuchs, A. R. 1985. Oxytocin in animal parturition. In Oxytocin: Clinical and Laboratory Studies. J. A. Amico and A. G. Robinson, editors. Elsevier, Amsterdam. 207-235.

5. Chan, W. Y. 1987. Enhanced prostaglandin synthesis in the parturient rat uterus and its effects on myometrial oxytocin receptor concentrations. Prostaglandins. 34:889-902.

6. Casey, L. M., and P. C. MacDonald. 1988. Biomolecular processes in the initiation of parturition: decidual activation. Clin. Obstet. Gynecol. 31:533-552.

7. Mitchell, B. F., and J. R. G. Challis. 1988. Estrogen and progesterone metabolism in human fetal membranes. In Physiology and Biochemistry of $\mathrm{Hu}$ man Fetal Membranes. B. F. Mitchell, editor. Perinatology Press, Ithaca, NY. 5-28.

8. Mitchell, B. F., B. Cruickshank, D. McLean, and J. Challis. 1982. Local modulation of progesterone production in human fetal membranes. J. Clin. Endocrinol. Metab. 55:1237-1239.

9. Chibbar, R., R. Hobkirk, and B. F. Mitchell. 1986. Sulfohydrolase activity for estrone sulfate and dehydroepiandrosterone sulfate in human fetal membranes and decidua around the time of parturition. J. Clin. Endocrinol. Metab. 63:1-8.

10. Okazaki, T., M. L. Casey, J. R. Okita, P. C. MacDonald, and J. M. Johnston. 1981. Initiation of of human parturition. XII. Biosynthesis and metabolism of prostaglandins in human fetal membranes and uterine decidua. Am. J. Obstet. Gynecol. 139:373-381.

11. Olson, D. M., K. Skinner, and J. R. G. Challis. 1983. Prostaglandin output in relation to parturition by cells dispersed from human intrauterine tissues. $J$. Clin. Endocrinol. Metab. 57:694-699.

12. Dawood, M. Y., D. Yeidorkala, D. Trevedi, and F. Fuchs. 1979. Oxytocin in maternal circulation and amniotic fluid during pregnancy. J. Clin. Endocrinol. Metab. 49:429-434.

13. Leake, R. D., R. E. Weitzman, T. H. Glatz, and D. H. Fisher. 1981 Plasma oxytocin concentrations in men, nonpregnant women and pregnant women before and during spontaneous labor. J. Clin. Endocrinol. Metab. 53:730-733.

14. Amico, J. A., S. M. Seif, and A. G. Robinson. 1984. Studies of oxytocin in plasma of women during hypocontractile labor. J. Clin. Endocrinol. Metab. 58:274-279.

15. Guillon, G., M. N. Balestre, J. M. Roberts, and S. P. Bottari. 1987. Oxytocin and vasopressin: Distinct receptors in myometrium. J. Clin. Endocrinol. Metab. 64:1129-1135.

16. Chard, T. 1989. Fetal and maternal oxytocin in human parturition. Am.J. Perinatol. 6:145-152.

17. Mitchell, B. F., and W. A. Powell. 1984. Progesterone production by human fetal membranes: an in vitro incubation system for studying hormone production and metabolism. Am. J. Obstet. Gynecol. 148:303-309.

18. Schwartz, A. L., C. S. Forster, P. A. Smith, and G. C. Liggins. 1977 Human amnion metabolism. I. In vitro maintenance. Am. J. Obstet. Gynecol. 127:470-474.

19. Ausubel, F. M., R. Breut, R. E. Kingston, D. D. Moore, J. G. Seedman J. A. Smith, and K. Struhl. 1990. Current Protocols in Molecular Biology. John Wiley \& Sons, Inc., New York. 4.2.3, 4.5.1, 4.7.1.

20. Chibbar, R., J. G. Toma, B. F. Mitchell, and F. D. Miller. 1990. Regulation of neural oxytocin gene expression by gonadal steroids in pubertal rats. $\mathrm{Mol}$. Endocrinol. 4:2030-2039.

21. Rehbein, M., M. Hillers, E. Mohr, R. Ivell, S. Morley, H. Schmale, and D. Richter. 1986. The neurohypophyseal hormones vasopressin and oxytocin: precursor structure, synthesis and regulation. Biol. Chem. Hoppe-Seyler. 367:695704.

22. Miller, F. D., G. Ozimek, R. J. Milner, and F. E. Bloom. 1989. Regulation of neuronal oxytocin mRNA by ovarian steroids in the mature and developing hypothalamus. Proc. Natl. Acad. Sci. USA. 86:2468-2472.

23. Melton, D. A., D. A. Krieg, M. R. Rabaphiati, T. Maniatis, K. Zinn, and M. R. Green. 1984. Efficient in-vitro synthesis of biologically active RNA and RNA hybridization probes from plasmids containing a bacteriophage SP6 promoter. Nucleic Acids Res. 12:7035-7056.

24. Gunning, P., P. Ponte, H. Okayama, J. Engel, M. Blau, and L. Kedes. 1983. Isolation and characterization of full length cDNA clones for human $\alpha, \beta$, and $\gamma$ actin mRNA's: skeletal but not cytoplamsic actins have an amino terminal cysteine that is subsequently removed. Mol. Cell. Biol. 3:787-795.

25. Ivell, R., K. Furuya, B. Brackman, Y. Dawood, and F. Khan-Dawood 1990. Expression of the oxytocin and vasopressin genes in human and baboon gonadal tissues. Endocrinology. 127:2990-2996.
26. Van Tol, H. H. M., E. L. M. Bolwerk, B. Liu, and J. P. M. Burbach. 1988 Oxytocin and vasopressin gene expression in the hypothalamo-neurohypophyseal system of the rat during the estrous cycle, pregnancy and lactation. Endocrinology. 122:945-951.

27. Shukovski, L., D. L. Healy, and J. K. Findlay. 1989. Circulating immunoreactive oxytocin during the human menstrual cycle comes from the pituitary and is estradiol dependent. J. Clin. Endocrinol. Metab. 68:455-460.

28. Challis, J. R. G., and D. M. Olson. 1988. Parturition. In The Physiology of Reproduction. E. Knobil and J. Neill, editors. Raven Press, New York. 21772216.

29. Foo, N.-C., D. Carter, D. Murphy, and R. Ivell. 1991. Vasopressin and oxytocin gene expression in rat testis. Endocrinology. 128:2118-2128.

30. Ivell, R., and D. Richter. 1984. The gene for the hypothalamic peptide hormone oxytocin is highly expressed in the bovine corpus luteum: biosynthesis, structure and sequence analysis. EMBO (Eur. Mol. Biol. Organ.) J. 3:2351-2354.

31. Zeeri, M., J. R. Nevins, and J. E. Darnell. 1982. Newly formed mRNA lacking polyadenylic acid enters the cytoplasm and the polyribosomes but has a shorter half life in the absence of polyadenylic acid. Mol. Cell. Biol. 2:517-525.

32. Bernstein, P., and J. Ross. 1989. Poly(A), poly(A) binding protein and the regulation of mRNA stability. Trends Biochem. Sci. 14:373-377.

33. Zingg, H. H., and D. L. Lefebvre. 1989. Oxytocin mRNA: increase of polyadenylate tail size during pregnancy and lactation. Mol. Cell. Endocrinol. 65:59-62.

34. Carter, D. A., and D. Murphy. 1989. Independent regulation of neuropeptide mRNA level and poly(A) tail length. J. Biol. Chem. 264:6601-6603.

35. Ivell, R., K. H. Brackett, M. S. Fields, and D. Richter. 1985. Ovulation triggers oxytocin gene expression in the bovine ovary. FEBS (Fed. Eur. Biochem. Soc.) Lett. 190:263-267.

36. Khan-Dawood, F. S., and M. Y. Dawood. 1983. Human ovaries contain immunoreactive oxytocin. J. Clin. Endocrinol. Metab. 57:1129-1132.

37. Guldenar, S. E. F., D. C. Wathes, and B. T. Pickering. 1984. Immunocytochemical evidence for the presence of oxytocin and neurophysin in the large cells of the bovine corpus luteum. Cell Tissue Res. 237:349-353.

38. Mohr, E., A. Zhou, N. A. Thorn, and D. Richter. 1990. Rats with physically disconnected hypothalamo-pituitary tracts no longer contain vasopressinoxytocin gene transcripts in the posterior pituitary lobe. FEBS (Fed. Eur. Bio chem. Soc.) Lett. 263:332-336.

39. Jirikowski, G. F., P. P. Sanna, and F. E. Bloom. 1990. mRNA coding for oxytocin is present in axons of the hypothalamo-neurohypophyseal tract. Proc. Natl. Acad. Sci. USA. 87:7400-7404.

40. Fuchs, A. R., R. Romero, D. Keefe, M. Parra, E. Oyarzun, and E. Behnke. 1991. Oxytocin secretion and human parturition: pulse frequency and duration increases during spontaneous labour in women. Am. J. Obstet. Gynecol. 165:1515-1523.

41. Richard, S., and H. H. Zingg. 1990. The human oxytocin gene promoter is regulated by estrogens. J. Biol. Chem. 265:6098-6103.

42. Haluska, G. J., N. B. West, M. J. Novy, and R. M. Brenner. 1990. Uterine estrogen receptors are increased by RU486 in late pregnant rhesus macaques but not after spontaneous labor. J. Clin. Endocrinol. Metab. 70:181-186.

43. Skinner, K. A., and J. R. G. Challis. 1985. Changes in the synthesis and metabolism of prostaglandins by human fetal membranes and decidua at labor. Am. J. Obstet. Gynecol. 151:519-523.

44. Olson, D. M., K. Skinner, and J. R. G. Challis. 1983. Estradiol-17 $\beta$ and 1-hydroxyestradiol-17 $\beta$ induced differential production of prostaglandins by cells dispersed from human intrauterine tissues at parturition. Prostaglandins. 25:639-651

45. Fuchs, A. R., P. Husslein, and F. Fuchs. 1981. Oxytocin and the initiation of human parturition. II. Stimulation of prostaglandin production in human decidua by oxytocin. Am. J. Obstet. Gynecol. 141:694-698.

46. Chen, W. Y. 1987. Enhanced prostaglandin synthesis in the parturient rat uterus and its effects on myometrial oxytocin receptor concentrations. Prostaglandins. 34:889-902.

47. Moore, J. J., R. M. Moore, and D. Vanderkooy. 1991. Protein kinase-C activation is required for oxytocin induced prostaglandin production in human amnion cells. J. Clin. Endocrinol. Metab. 72:1073-1080.

48. Fuchs, A. R., F. Fuchs, P. Husslein, M. S. Soloff, and M. J. Fernstrom. 1982. Oxytocin receptors and human parturition: a dual role for oxytocin in the initiation of labor. Science (Wash. DC). 215:1396-1398.

49. Fuchs, A. R., F. Fuchs, P. Husslein, and M. S. Soloff. 1984. Oxytocin receptors in pregnant human uterus. Am. J. Obstet. Gynecol. 150:734-741.

50. Fukai, H., K. Den, H. Sakamoto, H. Hodaira, and S. Takagi. 1984. Study of oxytocin receptors: oxytocin and $\mathrm{PGF}_{2} \alpha$ receptors in human myometria and amnion-decidua complex during pregnancy and labor. Endocrinol. Jpn. 31:565572.

51. Husslein, P., A. R. Fuchs, and F. Fuchs. 1981. Oxytocin and the initiation of human parturition. 1. Prostaglandin release during induction of labor with oxytocin. Am. J. Obstet. Gynecol. 141:688-693.

52. Fuchs, A. R., P. Husslein, F. Kofler, I. Grunberger, A. Rasmussen, and J. 
Rehnstrom. 1983. Effect of cervical cap application of $\mathrm{PGE}_{2}$ on plasma oxytocin and 13,14-dihydro-15-keto-PGF ${ }_{2}$ in pregnant women at term. Br. J. Obstet. Gynaecol. 90:612-617.

53. Garfield, R. E., E. E. Daniel, M. Dukes, and J. D. Fitzgerald. 1982. Changes in gap junctions in myometrium of guinea pig at parturition and abortion. Can. J. Physiol. Pharmacol. 60:335-341.

54. Soloff, M. S. 1988. The role of oxytocin in the initiation of labor, and oxytocin-prostaglandin interactions. In The Onset of Labor: Cellular and Integrative Mechanisms. D. McNellis, J. Challis, P. MacDonald, P. Nathanielsz, and J. Roberts, editors. Perinatology Press, Ithaca, NY.

55. Romero, R., M. Mazor. 1988. Infection and preterm labor. Clin. Obstet. Gynecol. 31:553-584.

56. Romero, R., M. Sirtoi, E. Oyarzun, C. Avila, M. Mazor, R. Callahan, V. Sabo, A. P. Athanassiadis, and J. C. Hobbins. 1989. Infection and labor. V. Prevalence, microbiology, and clinical significance of intraamniotic infections in women with preterm labor and intact membranes. Am. J. Obstet. Gynecol. 161:817-824.

57. Christensen, J. D., E. W. Hansen, and B. Fjalland. 1990. Influence of interleukin- $1 \beta$ on the secretion of oxytocin and vasopressin from the isolated rat neurohypophysis. Pharmacol. Toxicol. 67:81-83.

58. Kastings, N. W. 1986. Characteristics of body temperature, vasopressin and oxytocin responses to endotoxin in the rat. Can. J. Physiol. Pharmacol. 64:1575-1578.
59. Mohr, E., V. Bahnsen, C. Kiessling, and D. Richter. 1988. Expression of the vasopressin and oxytocin gene in rats occurs in mutually exclusive sets of hypothalamic neurons. Science (Wash. DC). 242:144-148.

60. Mitchell, M. D., R. J. Romero, C. Avila, J. T. Foster, and S. S. Edwin. 1991. Prostaglandin production by amnion and decidua cells in response to bacterial products. Prostaglandins Leukotrienes Essent. Fatty Acids. 42:167-169.

61. Mitchell, M. D., S. Edwin, and R. J. Romero. 1990. Prostaglandin biosynthesis by human decidual cells: effects of inflammatory mediators. Prostaglan dins Leukotrienes Essent. Fatty Acids. 41:35-38.

62. Romero, R., K. R. Manogue, M. D. Mitchell, Y. K. Wu, E. Oyarzum, J. C. Hobbins, and A. Cesami. 1989. Infection and labor. IV. Cachectin-tumor necrosis factor in the amniotic fluid of women with intraamniotic infection and preterm labor. Am. J. Obstet. Gynecol. 161:336-341.

63. Lamont, R. F., M. P. Rose, and M. G. Elder. 1985. Effect of bacterial products on prostaglandin E production by amnion cells. Lancet. 2:1331-1333.

64. Akerlund, M., P. Stromberg, A. Hauksson, L. F. Andersen, J. Lyndrup, J. Trojnar, and P. Melin. 1987. Inhibition of uterine contractions of premature labour with an oxytocin analogue: results from a pilot study. Br. J. Obstet. Gynaecol. $94: 1040-1044$.

65. Wilson, L., Jr., M. T. Parsons, and G. Flouret. 1990. Inhibition of spontaneous uterine contractions during the last trimester in pregnant baboons by an oxytocin antagonist. Am. J. Obstet. Gynecol. 163:1875-1882. 